
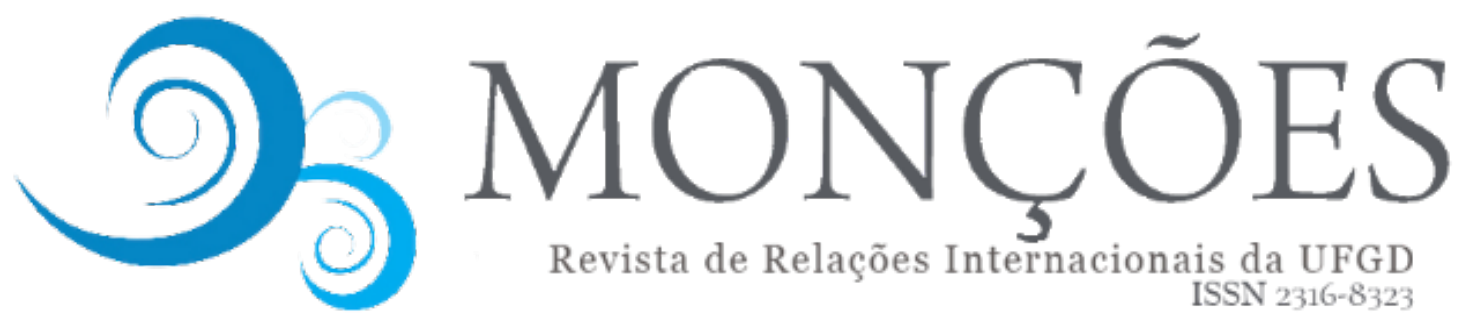

\title{
FEMINISMO PÓS-COLONIAL NAS RELAÇÕES INTERNACIONAIS? INTERSECÇÕES E DIÁLOGOS TEÓRICOS PARA REFLETIR SOBRE GÊNERO, REFÚGIO E VIOLÊNCIA NO SUL GLOBAL
}

\author{
NICOLE XAVIER DA CUNHA MINVIELLE \\ Mestranda no Programa de Pós-Graduação em Relações Internacionais (PPGRI) da \\ Universidade de Brasília.
}

\begin{abstract}
RESUMO: O presente estudo propõe um exercício para pensar como o feminismo pós-colonial, emergido das intersecções e dos diálogos entre as abordagens teóricas feministas e pós-coloniais, permite refletir sobre temas das Relações Internacionais. A hipótese é que a intersecção das categorias de raça, de gênero e de classe, oferecidas pelo feminismo pós-colonial, possibilita compreender temas da agenda internacional, como o gênero, a violência e o refúgio, a partir de uma visão do Sul Global. Este trabalho está divido em três seções. A primeira é dedicada à apresentação e discussão do feminismo pós-colonial nas Relações Internacionais. Em seguida, na segunda seção, discute-se como a lei internacional do refúgio, as motivações do deslocamento forçado e a construção da imagem da pessoa refugiada podem ser pensados a partir do Sul Global. Mais especificamente, na última seção, trabalha-se essas três dimensões para pensarmos a violência de gênero contra mulheres em contextos de refúgio: a insuficiência do conceito da violência de gênero, as identidades que moldam a experiência feminina e seus motivos de deslocamento e a construção da imagem da mulher refugiada. Os resultados do artigo colaboram para a construção de um arcabouço teórico capaz de refletir sobre temáticas das Relações Internacionais, a partir de perspectivas críticas que valorizem as identidades, as narrativas e as experiências de indivíduos e, especificamente, das mulheres.
\end{abstract}

PALAVRAS-CHAVE: feminismo pós-colonial, violência, refúgio.

\section{POSTCOLONIAL FEMINISM IN INTERNATIONAL RELATIONS? INTERSECTIONS AND THEORETICAL DIALOGUES TO REFLECT ON GENDER, REFUGEE AND VIOLENCE IN THE GLOBAL SOUTH}

\begin{abstract}
This study proposes an exercise to think about how postcolonial feminism, emerged from the intersections and dialogues between feminist and postcolonial theoretical approaches, allows us to reflect on International Relations themes. The hypothesis is that the intersection of categories as race, gender, and class offered by postcolonial feminism makes it possible to understand issues on the international agenda, such as gender, violence, and refuge, from the Global South perspective. This paper is divided into three sections. The first is dedicated to the presentation and discussion of postcolonial feminism in International Relations. Then, in the second section, we discuss how the international refugee law, the motivations of forced displacement, the representation and the construction of the image of refugees can be thought from a Global South perspective. More specifically, in the last section, we work on these three dimensions to think about gender violence against women in refugee contexts: the concept of gender violence, the identities that shape women's experiences in the refugee context and the construction of the refugee women image. The results of the article contribute to the construction of a theoretical framework capable of reflecting on International Relations themes, from critical perspectives that value the identities, narratives, and experiences of individuals and women from the Global South.
\end{abstract}

KEYWORDS: postcolonial feminism; violence; refugee 


\section{Introdução}

Ao redor do mundo, o United Nations High Commissioner for Refugees UNHCR (2019) estima que 70,8 milhões de homens, de mulheres e de crianças se encontram deslocados de suas terras de origem. Devido às perseguições, aos conflitos, às agressões e às violações de direitos humanos, se encontram deslocados internamente no país de origem ou asilados e refugiados em outro país. Uma vez que o fenômeno ocorre no cenário internacional, presumir-se-ia a migração como um tema de pesquisa por excelência das Relações Internacionais (RI). No entanto, Weiner (1992), Haddad (2008), Betts e Loescher (2011), concordam que por muito tempo a literatura da área negligenciou a produção de estudos referentes à temática. Para explicar este lapso, Weiner (1992) e Hollifield (2008) observaram que o pensamento realista no período da Guerra Fria foi responsável por dividir a política internacional em temas de alta política, relativos à segurança e à política externa dos Estados, e de baixa política, relacionados às questões sociais e econômicas. As migrações, por não configurarem, até então, um tema dos estudos de segurança ou de política externa dos Estados, não foi objeto de análise das Relações Internacionais até os anos 1990 (HOLLIFIELD, 2008). Ferris (2004) complementa esta ideia, afirmando que as discussões sobre refúgio foram, muitas vezes, interpretadas como tragédias inevitáveis ou como uma condição necessária para a mudança social. Ou seja, nos grandes debates de Guerra e Paz, não se fazia necessário estudar um tema que era uma consequência "natural" da guerra.

Foi somente com o final da Guerra Fria que a migração adquiriu urgência teórica e empírica para o mundo. O aumento vertiginoso do número de pessoas fugindo de seus países de origem por motivos econômicos, desastres ambientais e conflitos civis e militares, combinado com a diversificação de abordagens e de temas na agenda internacional, permitiu que o refúgio passasse a ser compreendido como uma questão global que deveria ser pensada teoricamente pelas Relações Internacionais (WEINER, 1992; TROELLER, 2003). As dificuldades que as teorias convencionais tinham em responder às complexidades e às incertezas criadas pelo fim da Guerra Fria, como a dissolução do bloco soviético, o fortalecimento da União Europeia, a ascensão dos temas sociais e a relevância das ameaças ecológicas e econômicas produziram uma virada crítica nas Relações Internacionais (ZEHFUSS, 
2013). As concepções teóricas críticas às vertentes positivistas surgiram a fim de repensar as ontologias, as epistemologias e as metodologias que haviam até então dominado o campo de estudo. Este esforço intelectual comum às teorias críticas, pós-modernas, pós-coloniais, construtivistas e feministas, possibilitou a ampliação da agenda internacional, trazendo à tona novas interpretações de temas já consagrados na área, assim como novas perguntas e respostas que as teorias positivistas não tinham interesse e/ou capacidade em formular (TICKNER, 2001; WIBBEN, 2004).

As primeiras abordagens feministas nas Relações Internacionais tiveram por objetivo revelar que o sistema internacional é profundamente marcado por uma visão parcial da realidade: a visão do homem ocidental da elite (TICKNER, 1992). A teoria pós-colonial também trouxe para as RI a preocupação epistemológica de questionar a universalidade das categorias do pensamento científico social moderno e das disciplinas nas quais ele é dividido, trazendo as categorias de raça e classe para o centro do debate a fim de pensar como a história é narrada e a política é compreendida a partir da visão de uma parte do globo: o Norte Global (SETH, 2013).

Diante disso, o presente artigo propõe um exercício para pensar como o feminismo pós-colonial, emergido a partir das intersecções e dos diálogos entre as abordagens teóricas feministas e pós-coloniais, permite refletir sobre temas das Relações Internacionais. Para demonstrar como as categorias de raça, de gênero e de classe contribuem para abordar o refúgio a partir de uma visão do Sul Global, este estudo é dividido em três seções. A primeira seção é dedicada à apresentação e à discussão do feminismo pós-colonial nas Relações Internacionais. Em seguida, na segunda seção, discute-se como a lei internacional do refúgio, as motivações do deslocamento forçado e a construção da imagem da pessoa refugiada podem ser pensados a partir do Sul Global. Mais especificamente, na última seção, trabalha-se essas três dimensões para pensarmos a violência de gênero contra mulheres em contextos de refúgio: a insuficiência do conceito da violência de gênero, as identidades que moldam a experiência feminina e seus motivos de deslocamento e a construção da imagem da mulher refugiada. 
2. Feminismo pós-colonial nas Relações Internacionais: intersecções entre raça, classe e gênero

O feminismo e o pós-colonialismo compartilham uma visão crítica das Relações Internacionais ao prestarem atenção às margens e aos indivíduos marginalizados. Ambas as abordagens teóricas se posicionam frente ao mesmo objetivo: criticar abordagens convencionais que se diziam neutras, universais, objetivas e estáticas e inserir questões de representação, de vozes e de marginalização (NAIR, 2017; BAHRI, 2013). Tais perspectivas apresentam, no entanto, impasses e lacunas. O feminismo, por exemplo, exerceu um papel extremamente importante ao inserir o gênero como categoria de análise, mas no seu princípio, se demonstrou hesitante em trabalhar as implicações das categorias de raça e de classe no sistema de poder internacional (NAIR, 2017). Já os estudos póscoloniais, que entraram no campo por uma literatura crítica marxista, pós-moderna e feminista, introduziram os debates sobre as assimetrias de raça e de classe, mas deixaram as questões de gênero como secundárias em favor das discussões da descolonização e do imperialismo (BAHRI, 2013). Esta seção visa apresentar o feminismo pós-colonial, que ao beber de ambas as fontes, oferece elementos para preencher lacunas teóricas sobre as intersecções entre colonialismo, patriarcado e capitalismo (BAHRI, 2013).

Para compreendermos os fundamentos da teoria pós-colonial, é preciso recuar até um dos seus precursores: Edward Said. A obra de Said (1990) é o ponto de partida para refletir como o Ocidente moldou a maneira como enxergamos e pensamos a região do Oriente Médio. Ao estudar o colonialismo britânico e francês no século XIX e o imperialismo dos Estados Unidos no século XX no Oriente Médio, Said (1990) sugeriu a construção de um sistema racial de representação entre os europeus, racionais, civilizados e masculinos, e, portanto, superiores, e os orientais, irracionais, bárbaros, preguiçosos e femininos, e consequentemente, inferiores. Esse conhecimento foi produzido pela ciência, arte, literatura e discursos e se tornou um componente ideológico importante para o poder colonial. Denominado de Orientalismo, este processo foi praticado de diversas formas ao longo dos séculos, mas no âmago, seu objetivo continuou o mesmo: projetar uma imagem dos povos orientais como incivilizados e exóticos para justificar o domínio ocidental nos âmbitos 
político, econômico, social e cultural (SAID, 1990). Para explicar a origem e a perpetuação das assimetrias, das estruturas de poder vigentes, da dominação e das resistências, mesmo após o fim dos impérios coloniais no século $X X$, os estudos pós-coloniais sugerem ler o mundo a partir da intersecção das lentes de classe e de raça (CHOWDRY; NAIR, 2002; NAIR, 2017).

A primeira categoria é utilizada para pensar como a colonização e o imperialismo estabeleceram uma estrutura econômica mundial hierarquizada, por meio da qual Estados europeus controlavam e exploravam os recursos naturais, materiais e populacionais de países no Sul Global (LOOMBA, 1998). Essa exploração teve origem em 1492, com a descoberta das Américas, e moldou o mundo no qual vivemos. Diferente das narrativas tradicionais, Seth (2013) aborda que o sistema internacional como o conhecemos hoje não é simplesmente fruto de um desenvolvimento endógeno na Europa, mas de interconexões estruturais entre as diferentes partes do mundo. $O$ desenvolvimento do capitalismo e das instituições e normas europeias, "coincidiu" com o espólio de ouro e de prata nas Américas, a escravização de pessoas originárias da África, a fundação das empresas britânicas e holandesas das Índias Orientais e a abertura de mercados coloniais e de comércios desiguais. Todos esses fenômenos foram a base do desenvolvimento europeu e consolidou também uma estrutura internacional moldada pelas formas coloniais de se fazer política, economia e comércio (SETH, 2013).

O fortalecimento econômico, político e cognitivo dos países europeus passou pela consolidação do direito de exploração baseado em um sistema de raça, um conceito científico e antropológico criado para naturalizar a inferioridade dos sujeitos de "cor" (CHOWDHRY; NAIR, 2002). Expoente dos estudos decoloniais ${ }^{1}$ na América Latina, Quijano (2005) explica que a ideia de raça, como a conhecemos hoje, não existia antes da colonização da América, mas foi criada como instrumento de hierarquização social. A raça não possuía nenhuma relação com a estrutura biológica do organismo humano, mas a invenção do índio, do negro, do mestiço e do branco foi relacionada a existência de "cores" da pele e de fenótipos diferentes, tornando-se o primeiro critério universal para a categorização de populações no mundo (QUIJANO, 2005). A criação do mito "das raças de baixa eficiência social"

\footnotetext{
${ }^{1} \mathrm{Na}$ corrente do pensamento pós-colonial, os estudos decoloniais se originam em $1998 \mathrm{com}$ um grupo latino-americano composto por Enrique Dussel, Immanuel Wallerstein, Edgardo Lander, Anibal Quijano, Walter Mignolo e Maria Lugones.
} 
(DARBY, 2016), fundamentou o extermínio dos povos indígenas, a escravização dos povos africanos e a colonização de sociedades na Ásia em virtude da criação de um desenvolvimento no qual o europeu ensinaria e comandaria e os não europeus "contribuiriam" para o desenvolvimento (KRISHNA, 2006). Para Quijano, a colonização significou um sistema de poder que nasceu no século XIV com a descoberta da América Latina e foi baseado no controle da política, dos recursos, do trabalho e da população. A colonialidade se refere à continuação do domínio econômico, político e cognitivo, mesmo após as independências das Américas, que tem como base a divisão racial, sexual e do trabalho.

Ao final da Guerra Fria, a doutrina econômica e política neoliberal intensificou a periferização do Sul Global nos âmbitos econômico, político, social e cultural ao pregar o "fim da ideologia" e o "fim da história", uma vez que todas as regiões do mundo estariam interligadas por uma estrutura de Estados modernos e uma economia liberal (CHOWDHRY; NAIR, 2002). Foi também neste momento, que as iniciativas pós-coloniais emergiram nas Relações Internacionais para questionar como a disciplina foi dominada no século $X X$, e continuou no século $X X I$, por narrativas históricas e pela produção de conhecimentos da Europa e da América do Norte (SETH, 2013; JONES, 2006). Os estudos pós-coloniais teceram novos debates, ao discutirem como as práticas de domínio simbólico, cognitivo e material não se extinguiram com o fim da colonização, mas continuaram agindo nos âmbitos econômicos, políticos, institucionais, sociais, culturais e legais dos Estados, dos povos e das estruturas que organizam o sistema internacional (CHOWDHRY; NAIR, 2002; JONES, 2006; NAIR, 2017).

Teoricamente, uma abordagem pós-colonial nas Relações Internacionais visa compreender como "as sociedades, os governos e as pessoas nas regiões antigamente colonizadas experimentam as Relações Internacionais" (NAIR, 2017, p. 69). Em outras palavras, aponta os impactos que o colonialismo, imperialismo e orientalismo tiveram na construção do sistema internacional e como as assimetrias de conhecimento e poder marginalizaram o mundo não ocidental. Assim, o póscolonialismo traz diferentes perspectivas e contribuições a partir do Sul Global sobre temas e eventos, como os regimes de direitos humanos, a segurança, o comércio, o capitalismo global e a migração (NAIR, 2017; CHOWDHRY; NAIR, 2002). No entanto, outra categoria se faz necessária para compreender as complexas relações 
de assimetrias que perpassam o sistema internacional e os temas acima citados: 0 gênero.

Foi na janela teórica crítica aberta ao final da Guerra Fria, que o gênero passou a ser pensado como uma categoria útil de análise e a mulher como um agente a ser estudado nas Relações Internacionais. A ascensão de abordagens teóricas feministas acompanhou um movimento mais amplo das ciências sociais, mas que chegou tardiamente e teve nas Relações Internacionais, um dos campos mais resistentes à sua inserção (TICKNER, 2002). A primeira onda de estudos feministas nas Relações Internacionais contou com obras de Jean Elshtain, Cynthia Enloe, e Ann J. Tickner, que integraram a perspectiva conhecida como ponto de vista feminista. As três autoras foram pioneiras em identificar o papel e a posição que as mulheres ocupam na política global, denunciar a sua exclusão dos discursos teórico e da narrativa histórica internacional e construir críticas feministas às epistemologias e ontologias das tradições liberal e realista. Epistemologicamente, "[...] o feminismo de ponto de vista chama a atenção para as formas de conhecimento que as mulheres possuem ao desvendar e estudar suas experiências, pois isso proporciona um prisma sobre como a política global é sentida e constituída por seres reais" (HANSEN, 2010, p. 22, tradução própria). Num segundo momento, na metade da década de 90 , as pesquisadoras de vertentes pós-estruturais defenderam que não bastava identificar as mulheres na política internacional, mas também problematizar como o discurso engendrado determinou a construção de papeis desiguais e conceitos androcêntrico no cenário internacional. As autoras que compuseram este grupo, como Christine Sylverstein e Roxanne Lynn Doty, se preocuparam em identificar como os discursos constroem o entendimento, as ações e as posições em relação ao corpo feminino (HANSEN, 2010).

As primeiras autoras feministas das Relações Internacionais abriram importantes caminhos de estudo para compreender como as desigualdades de gênero impactam e denotam posições assimétricas da mulher em relação ao homem em um conjunto de questões sociais, políticas, econômicas e culturais. No campo das Relações Internacionais, foram também personalidades como Ann J Tickner, Cynthia Enloe e Jin Pettman que abriram os primeiros espaços para discutir questões sobre raça, colonialismo e subalternidade. No entanto, não avançaram na incorporação das categorias de raça e classe, e os debates sobre colonialismo e 
imperialismo, no mesmo nível de importância das análises de subordinação de gênero (CHOWDHRWY; LING, 2018).

A primeira contribuição do feminismo pós-colonial é, portanto, compreender a existência de intersecções entre três principais categorias: gênero, classe e raça. Por intersecção compreende-se a existência de identidades que se cruzam para moldar experiências e narrativas dos sujeitos e que, por este motivo, devem ser pensadas em conjunto (CRENSHAW, 1991). Ao lado das categorias de classe e de raça, já anteriormente explicadas, o gênero é o mais antigo e mais duradouro instrumento de dominação social e universal (QUIJANO, 2005). Como categoria de análise, refuta que as relações de desigualdades entre os homens e as mulheres são biologicamente e essencialmente dadas ou naturais, mas identificar a existência de papeis socialmente e historicamente construídos e impostos sobre os corpos sexuados (SCOTT, 1990). Nesse sentido, a interseccionalidade significa compreender que o sistema de poder global capitalista e racial atua em consonância com o sistema engendrado e suas múltiplas faces de poder (LUGONES, 2008).

Para o feminismo pós-colonial, o colonialismo e o patriarcado não são sistemas excludentes, pelo contrário, possuem pontos de intersecção que permitem compreender a experiência das mulheres no Sul Global. Uma segunda contribuição é pensar nas múltiplas faces da sustentação desse patriarcado. É importante apontar que as relações desiguais de gênero não foram simplesmente impostas pelos colonizadores sem que tenha havido um sistema patriarcal no interior dessas comunidades. Para Loomba (1998), as estruturas patriarcais já existiam na sociedade antes de ser colonizada, mas são intensificadas e modificadas com a inserção das relações de colonizado/colonizador. Assim, o sistema engendrado passa a oferecer múltiplas faces: a opressão do homem colonizador, a opressão do homem colonizado que, passa a reafirmar o poder perdido devido a dominação de outros homens sobre as próprias mulheres, e o da mulher branca burguesa que reproduz o sistema heterossexual e patriarcal e mantêm os homens brancos no poder, apesar não ter acesso às tomadas de decisão (LUGONES, 2008).

Em 1987, Gayatri Chakravorty Spivak, teórica do movimento dos subalternos e uma das precursoras do feminismo pós-colonial, chamou a atenção para o que significa ser mulher no contexto colonial: "se, no contexto da produção colonial, o sujeito subalterno não tem história e não pode falar, o sujeito subalterno feminino 
está ainda mais profundamente na obscuridade" (2010, p. 67). Uma terceira contribuição é o que Spivak (2010) chamou de "violência epistêmica", ou seja, a negação da capacidade das mulheres do Terceiro Mundo em articular suas necessidades e suas experiências. Isso ocorreu devido à construção de um patriarcado homogêneo e universal pelo feminismo ocidental, pelo qual todas as mulheres estariam igualmente submetidas (MOHANTY,1984; BAHRI, 2013). Lugones (2008) explica que as mulheres ocidentais presumiram o compartilhamento das mesmas pressões sofridas pela dominação masculina, o que possibilitaria a criação de uma "irmandade natural". A universalidade das lutas emancipatórias feministas, na verdade, assumiu uma roupagem eurocêntrica, que não foi capaz de analisar e compreender as vidas das mulheres de outras classes, religiões, culturas, etnias e raças, que não fossem ocidentais (MOHANTY, 1984). Dessa forma, ao invés de compartilhar a luta e a emancipação, houve o silenciamento das mulheres do Sul Global. A cegueira das intersecções e das diferentes vozes e experiências, levou a um processo de empoderamento e emancipação desigual. As mulheres brancas e ocidentais se beneficiaram e perpetuaram a invisibilidade e a submissão das vivências das mulheres pobres, de cor e oriundas de países periféricos (AGATHANGELOU, 2002; HOOKS, 1984).

A interseccionalidade entre a raça, o gênero e a classe, e outras categorias, como a religião, a migração e a cultura são variáveis que denotam privilégios e submissões (MOHANTY, 1984; LOOMBA, 1998). As mulheres experimentam desigualdades baseadas no gênero, mas os níveis e as consequências das violências são diferenciados. E é por esse motivo que o feminismo pós-colonial está preocupado com o problema da representação a nível local: quem fala por ou na voz do feminismo pós-colonial? quem ouve? por quê? (CHOWDHRY; LING, 2018). O feminismo pós-colonial está preocupado em construir espaços de resistência, de narrativas e de práticas contra-hegemônicas (CHOWDHRY; LING, 2018). Este esforço é o que pretendeu-se demonstrar brevemente aqui, trazendo importantes autores e autoras engajados neste empreendimento de tornar visíveis as vozes, as histórias, os locais, as lutas e os movimentos das pessoas e das regiões marginalizadas (CHOWDHRY; LING, 2018). Neste sentido, na seção seguinte, busca-se pensar a temática do refúgio e das pessoas refugiadas no Sul Global a partir do arcabouço teórico aqui exposto. 


\section{O refúgio a partir da experiência do sul global}

Em geral, os estudos sobre fluxos de pessoas refugiadas priorizam os deslocamentos do Sul em direção ao Norte Global. Notícias divulgadas pelos principais veículos de comunicações internacionais e estudos acadêmicos acompanham de forma incessante a chamada "Crise Migratória" na Europa, mas como observado por Aguayo, Suhrke e Zolberg (1989), Said (2003), Weiner (1992) e Grimson (2011), o movimento migratório do sul para o norte e do leste para o oeste, é apenas um dos fluxos existentes no mundo, e tampouco configura o fluxo principal. Os maiores contingentes não estão no velho continente, mas nas regiões do Oriente Médio, da África e da Ásia, que abrigam 16,7 dos 20,4 milhões refugiados registrados no UNHCR (2019). Apesar de 83\% da população refugiada mundial ter por origem e destino o continente africano e asiático, as pesquisas acadêmicas das Relações Internacionais ainda são escassas em abordar o refúgio a partir da perspectiva do Sul Global (CHIMINI, 1998; DAWN, 2010). É neste sentido que uma abordagem pós-colonial pode contribuir para suprir essa lacuna.

Os movimentos forçados de pessoas e populações sempre estiveram presentes na história da humanidade, mas sob diferentes sentidos e contextos. Só podemos falar em migrações internacionais a partir dos séculos XVI e XVII, quando a Europa passou a se organizar em sistemas políticos soberanos e limitados por fronteiras conhecidos como Estados modernos (HADDAD, 2008; AGUAYO; SUKHRE; ZOLBERG, 1986; WEINER, 1992). Os primeiros migrantes e refugiados, nessa lógica moderna, fizeram parte dos projetos nacionais dos Estados europeus em formação. A partir de então, as migrações foram caracterizadas como internacionais por implicarem em deslocamentos de indivíduos submetidos aos diferentes sistemas político e jurídico de cada Estado (AGUAYO; SUKHRE, ZOLBERG, 1986; HADDAD, 2008; REIS, 2004).

Durante a década de 1950, o primeiro esforço coletivo foi empreendido para construir um aparato normativo e institucional para os refugiados. Logo após a Primeira Guerra Mundial, o desmantelamento dos grandes impérios Austro-Húngaro, Romanov, Otomano e Prussiano, produziu efeitos semelhantes ao processo de formação do Estado-nação. Excluíram contingentes populacionais que não se 
enquadravam nos padrões linguísticos, étnicos e religiosos impostos pelos Estados recém-formados (BETTS; LOESCHER, 2011). O aumento do volume de pessoas cruzando fronteiras devido às guerras mundiais, a incorporação de novos Estados no sistema internacional, a imposição de restrições migratórias por parte dos Estados e a assistência disponível reduzida, levou os países a criar categorias para delimitar os grupos de pessoas que teriam acesso à assistência internacional (AGUAYO; SUHRKE; ZOLBERG, 1989). Assim, em 1950, foi criada uma agência dentro da ONU, o Alto Comissariado das Nações Unidas para os Refugiados (ACNUR), que obteve a competência de promover e supervisionar a proteção dos direitos dos refugiados. No ano seguinte, a Convenção de Genebra (1951) convencionou que a pessoa refugiada deveria ser aquela que:

[...] em consequência dos acontecimentos ocorridos antes de $1^{\circ}$ de janeiro de 1951 e temendo ser perseguida por motivos de raça, religião, nacionalidade, grupo social ou opiniões políticas, se encontra fora do país de sua nacionalidade e que não pode ou, em virtude desse temor, não quer valer-se da proteção desse país, ou que, se não tem nacionalidade e se encontra fora do país no qual tinha sua residência habitual em consequência de tais acontecimentos, não pode ou, devido ao referido temor, não quer voltar a ele (ACNUR, 1951, p. 02).

Não obstante, a importância do reconhecimento institucional, a definição elaborada pelo ACNUR (1951) pareceu limitada quando comparada com os desafios que o refúgio trazia no cenário internacional. Moreira e Rocha (2010) argumentam que o refúgio era pensado como um fenômeno não permanente atrelado às guerras europeias, e que com a realocação dessas populações o problema seria resolvido. No entanto, nas décadas de 1960 e 1970, as novas ondas migratórias, desencadeadas pelos movimentos de descolonização na África e na Ásia, provaram que esta percepção estava errada (AGUAYO, SUHKRE, ZOLBERG, 1989). A categoria também não abrangia a totalidade das pessoas em situação de risco devido aos desastres ambientais, aos fatores econômicos e às crises alimentares (MOREIRA; ROCHA, 2010, p. 23) e "[...] não incluía um número vasto (mas difícil de calcular com precisão) de refugiados não declarados e considerados 'clandestinos"” (AGIER, 2006, p. 200). O conceito proposto pela ONU revelou-se excludente, seletivo e insuficiente para explicar o contínuo aumento dos fluxos migratórios e a 
diversificação dos lugares de origem, de destino e os motivos dos deslocamentos ${ }^{2}$. Diante disso, apresentamos três dimensões sobre o refúgio para as quais a teoria pós-colonial fornece recursos interpretativos.

Uma primeira dimensão, foi a construção de uma declaração sobre refúgio na América Latina que refletisse as experiências e as realidades dos deslocamentos forçados na região e respondesse às políticas globais insuficientes, acima tratadas. Em 1984, a Declaração de Cartagena, foi um documento, assinado no Colóquio realizado no México sobre Asilo e Proteção Internacional de Refugiados na América Latina, que a ampliou o significado de refúgio. Seu principal reconhecimento foi a ampliação de quem era a pessoa que tinha direito a solicitar pela proteção internacional. Em seu artigo terceiro, a declaração considerou como refugiado não apenas a pessoa que tenha fugido de seu país devido a guerras, mas também:

porque a sua vida, segurança ou liberdade tenham sido ameaçadas pela violência generalizada, a agressão estrangeira, os conflitos internos, a violação maciça dos direitos humanos ou outras circunstâncias que tenham perturbado gravemente a ordem pública (ACNUR, 1984, p. 03).

A elaboração deste documento refletiu a realidade da América Latina na década de 1980: os diversos regimes ditatórios e as constantes violações de direitos humanos. Conforme Jubilut e Madureira (2014), com a ascensão dos regimes ditatórias e, consequentemente, o desrespeito aos mecanismos de proteção de direitos humanos e a perseguição de pessoas, os fluxos de pessoas se deslocando na América Latina aumentou consideravelmente, especialmente na América Central, que na época contava com 2 milhões de pessoas deslocadas na região. A declaração se tornou uma resposta a um documento que não refletia as especificidades do Sul Global e concedeu às pessoas, que precisavam de proteção internacional, maiores chances de conseguir migrar para locais que the oferecessem segurança.

\footnotetext{
${ }^{2}$ Em 1967, o Protocolo relativo ao Estatuto dos Refugiados eliminou as limitações de espaço e tempo da Convenção de Genebra. Neste, reconheceu-se o surgimento de novas categorias de refugiados, que não foram incorporadas anteriormente, e expandiu-se o direito ao refúgio independente de anteceder ou não a data de 01 de janeiro de 1951 (ACNUR, 1967, p. 01). Atualmente, são a Convenção de Genebra de 1951 e o Protocolo Adicional de 1967 que regem os direitos e deveres das pessoas sob o status de refugiado.
} 
$\mathrm{Na}$ lei internacional do refúgio, a Declaração de Cartagena não possui um caráter vinculante, no entanto, o documento trouxe importantes contribuições ao promover uma série de mudanças e ampliação nas legislações dos países da região (JUBILUT; MADUREIRA, 2014). Essa prática, sob um olhar pós-colonial, significa um exemplo de reconstrução de narrativas e práticas, no qual os países latino americanos subverteram uma "norma" internacional para adaptá-la às suas necessidades e realidades. A continuação dos fluxos migratórios, com os deslocados internos na Colômbia e atualmente os refugiados venezuelanos ${ }^{3}$, demonstra a permanente necessidade da interpretação desse instrumento. A adoção do instrumento por países somente da América Latina, demonstra também, uma resistência do Norte Global em reconhecer as especificidades enfrentadas pelas pessoas que fogem de países devido à violação de direitos humanos.

Uma segunda dimensão a ser pensada, é no âmbito dos estudos acadêmicos sobre as motivações do deslocamento forçado no Sul Global. Desde as décadas de 1970 e 1980, os fluxos migratórios entre a Ásia e a África se tornaram os mais relevantes pela quantidade de pessoas e pela gravidade das crises humanitárias (SAID, 2003). Esse fenômeno levou a necessidade de mudanças nos estudos teóricos, para interpretar como a motivação desses deslocamentos humanos no Sul Global está ligada a múltiplas violências a nível nacional e internacional. A partir de uma visão do Sul Global, Aguayo, Suhkre e Zolberg (1989), apontam que os deslocamentos forçados estão ligados a violências que ocorrem tanto no âmbito local quanto internacional.

No que tange o nível local, os autores e a autora se referem à violência que ocorre dentro do país de origem, infligida diretamente por meio de guerras, ou indiretamente devido à falta de garantia aos direitos básicos e a uma vida normal aos nacionais, como acesso à saúde, educação, moradia, alimentação, trabalho, lazer e entre outros. A nível internacional, a violência está vinculada aos processos de descolonização, de nacionalismo e de globalização.

A descolonização e o fortalecimento do nacionalismo no continente afroasiático foi em si um processo violento de expulsão de pessoas do seu território de

\footnotetext{
${ }^{3}$ Em dezembro de 2019, o governo brasileiro reconheceu, por meio do procedimento facilitado de prima facie, a condição de refugiado de milhares solicitantes venezuelanos no Brasil. Essa decisão só foi possível ser tomada pois o Brasil é signatário da Declaração de Cartagena de 1984 e reconheceu que a situação de grave e generalizada violação de direitos humanos na Venezuela (ACNUR, 2019).
} 
origem. A delimitação de fronteiras territoriais dos novos países pressupunham a construção de uma unidade nacional, na qual elementos culturais como a religião, o idioma e a etnia, serviriam como aglutinador de uma comunidade dos quais alguns indivíduos pertenceriam, mas outras não (AGUAYO; SUHKRE; ZOLBERG, 1989; SAID, 2003). Em outras palavras, as pessoas que fizessem parte do grupo dominante seriam consideradas cidadãs do país, mas os "outros" seriam obrigados a cruzar fronteiras para buscar um novo local de pertencimento. Em consonância com esses dois processos do século XX, a globalização da década de 1990 acentuou os efeitos heterogêneos do sistema internacional. A divisão internacional do trabalho ao beneficiar algumas regiões do mundo e excluir outras, induziu ao subdesenvolvimento de economias no Sul Global, o acesso desigual ao comércio e aos meios de produção e o enfraquecimento de Estados (AGUAYO; SUHKRE; ZOLBERG, 1989; GILES; HYNDMAN, 2004). Frente aos dados recentes publicados pelo UNHCR (2019), as situações de violência e descolamento aumentam a cada ano e as desigualdades produzidas pela estrutura econômica internacional e a falta de garantias aos direitos fundamentais, se configuram, portanto, em deslocamentos forçados de pessoas em busca de condições básicas de meios de vida (BETTS; LOESCER, 2011).

Por fim, uma terceira dimensão da teoria pós-colonial é compreender a construção da imagem da pessoa refugiada como "subdesenvolvida" e como isso impacta na própria justificativa e aceitação da construção da política internacional do refúgio. Em 1951, o ACNUR foi criado como uma instituição ad hoc por um período de três anos para restabelecer os refugiados europeus das guerras mundiais em seus países ou realoca-los para novos países. (HYNDMAN, 2000). Nas décadas de 1970 e 1980, no entanto, a intensificação das ondas migratórias desencadeadas pelos movimentos de descolonização na África e na Ásia provaram que o deslocamento estava longe de ser um problema limitado a Europa no pós-guerra (AGUAYO, SUHKRE, ZOLBERG, 1989). Uma vez que essas regiões continuaram produzindo grandes fluxos de refugiados, a política do deslocamento foi repensada, deixando de apoiar uma estratégia ampla de reassentamento e asilo para defender uma política de contenção e assistência dos refugiados oriundos dos continentes afro-asiáticos (CHIMINI, 1998). 
Ao retomar a interpretação de Said (1990) sobre a construção de categorias dicotômicas de representação, Chimini (1998) escreve uma visão do Sul sobre a geopolítica dos estudos sobre refúgio. Explica que a imagem do refugiado "normal", homem, branco, europeu e anti-comunista, digno de receber exílio, contrastou com a nova imagem do refugiado de Terceiro Mundo. No final da Guerra Fria, quando a dinâmica dos fluxos migratórios se inverteu, do sul para o norte, a política de exílio também se modificou: se antes os países defendiam estratégias de reassentamentos de refugiados em novos países, com os "novos refugiados" oriundos dos continentes afro-asiáticos a lógica passa a ser fornecer formas de assistência e proteção que "barrem" o seu deslocamento. Hyndman (2000) explica que durante e após a Guerra Fria, enquanto a proteção convencional do asilo sofreu um declínio, a assistência humanitária se tornou amplamente difundida. A política do refúgio foi alterada com os governos do Norte Global financiando e politizando as ações nas regiões da Ásia e África para que não alcancem suas fronteiras. Desta maneira, diferente da política de reassentamento e de acolhimento que existia após a Segunda Guerra Mundial, as identidades dos "novos" refugiados refletiram na maneira como a ajuda humanitária respondeu por meio de campos de refugiados e de políticas de contenção no qual se mantêm os refugiados com recursos mínimos de vida, mas sem possibilidades de integração à comunidade local (AGIER, 2008).

Nos estudos sobre refúgio, as abordagens privilegiando o homem como sujeito do deslocamento ofuscou a percepção da mulher refugiada. Presumiu-se que era possível estudar as questões migratórias a partir de uma abordagem universal, pois uma vez que o indivíduo fosse percebido como refugiado, não seria relevante distinguir seu gênero. Para Krause e Zistel (2017, p. 03), o refúgio foi inicialmente pensado a partir do seguinte argumento androcêntrico: o homem, ao ocupar o espaço público, era alvo das perseguições vindas de conflito e, portanto, era o agente das migrações. As mulheres, tendo permanecido no espaço privado, não tinham a urgência de se locomover, e se o faziam, era para acompanhar a figura masculina da família. Na esteira das discussões sobre as motivações e as experiências femininas na jornada migratória, a próxima seção é dedicada para discutir mais especificamente a mulher dentro do contexto de refúgio do Sul Global. 


\section{As experiências de violências das mulheres refugiadas no sul global}

Em 2019, o número de pessoas refugiadas, registradas no sistema do UNHCR (2019), atingiu o marco de 20,4 milhões. Nos fluxos de deslocamento, estima-se que metade sejam compostos por mulheres que fogem das violências de gênero, classificadas pelo ACNUR (2003) como sexual, física, psicoemocional e socioeconômica, e buscam segurança em um novo país. Além de enfrentarem dificuldades comuns aos refugiados, como o acesso precário aos serviços de saúde, à educação, ao trabalho, à moradia e à justiça, as vivências femininas são atravessadas por um conjunto de hostilidades motivadas pela discriminação do gênero. A violência acompanha a mulher durante a sua jornada migratória: na fuga do país de origem, no movimento que implica na travessia das fronteiras, e no estabelecimento no país receptor (COCKBURN, 2004).

Estudar o refúgio a partir das lentes de gênero significa, portanto, entender como os papeis dos homens e das mulheres, que já foram socialmente construídos e delimitados na fase de pré-conflito, impactam as experiências femininas num ambiente de refúgio (FREEDMAN, 2007). Mas não podemos nos ater a isso. As situações de vulnerabilidade econômica, as construções da imagem de vítima e das situações de dependência pelas organizações ocidentais, a posição marginal que ocupam na economia e no Sul Global são também fundamentais para compreender as experiências das mulheres. Nesta seção iremos destacar três dimensões para pensarmos a partir do feminismo pós-colonial: (i) a insuficiência do conceito da violência de gênero no âmbito do refúgio; (ii) as identidades que moldam as inseguranças femininas no contexto de refúgio e (iii) a construção da imagem da mulher refugiada.

Legalmente, na Convenção de Genebra de 1951, não existe qualquer menção de perseguições em razão de gênero (FREEDMAN, 2007, p. 75). Na práxis, a falta de reconhecimento da perseguição com base no gênero, deixava as mulheres vítimas de violência legalmente desamparadas e sem mecanismos de proteção. Foi em 1991, que o ACNUR adotou o primeiro documento oficial sobre a mulher refugiada: o Guidelines on the Protection of Refugee Women. Neste documento a preocupação principal era apontar a falta de mecanismos de reconhecimento a violência de gênero como uma categoria de perseguição sofrida pela mulher, reconhecer a existência de violências no âmbito do refúgio, sobretudo sexual e 
física, e a falta de acesso a oportunidades econômicas (MARTIN, 2017). Paralelamente, em 1993, a Declaração das Nações Unidas para a Eliminação da Violência Contra a Mulher definiu pela primeira vez a violência de gênero como qualquer ação que: "resulte, ou possa resultar, dano ou sofrimento físico, sexual ou psicológico para as mulheres, incluindo as ameaças de tais atos, a coação ou a privação arbitrária de liberdade, que ocorra, quer na vida pública, quer na vida privada" (ONU MULERES, 1993, p. 01).

Ambos os documentos foram adotados no período em que se estabeleceu o Tribunal Penal Internacional para a ex-lugoslávia e a investigação do Comitê da Comunidade Europeia reconhecia, pela primeira vez, a existência de estupros em massa como arma de guerra (SEIFERT, 1996). A ONU revelou um comprometimento com as questões que envolviam a violência de gênero no âmbito da guerra e do refúgio, criando diversos documentos ao longo dos anos 1990 para fortalecer os mecanismos de proteção. No entanto, inicialmente, não conseguiu traduzir as especificidades locais onde realmente aconteciam as guerras e os fluxos de refugiados. Em resposta, a América Latina e a África sugeriram expansões no conceito de violência de gênero, que acompanhou também a multiplicação de documentos referentes a violência e a mulher refugiada dentro do ACNUR.

A Convenção de Belém do Pará, como ficou conhecida a Convenção Interamericana para Prevenir, Punir e Erradicar a Violência contra a Mulher, foi adotada em 1994 na América Latina, e trouxe uma ampliação sobre os lugares e as pessoas que perpetravam violência. A convenção trouxe o entendimento de que a violência não ocorre apenas no âmbito privado familiar ou público, mas também é "perpetrada ou tolerada pelo Estado ou seus agentes, onde quer que ocorra" (CIDH, artigo 2, 1994). Na América Latina, no qual as ditaduras e regimes militares cometeram graves violações de direitos humanos contra as mulheres, essa ampliação do conceito permitia caracterizar as diferentes formas de violências sexuais e torturas que eram permitidas e exercidas por agentes de Estados ${ }^{4}$ contra mulheres ditas subversivas. No contexto da migração no Sul Global, esse fato é de extrema importância visto que muitas das violações também são originárias da própria ajuda humanitária ou dos agentes estatais que deveriam proteger e

\footnotetext{
${ }^{4}$ Para maiores informações sobre o caso brasileiro, acessar o relatório da Comissão da Verdade, disponível aqui: < http://cnv.memoriasreveladas.gov.br/images/pdf/relatorio/volume_1_digital.pdf>. Acesso em: 22 jun. 2019.
} 
assegurar a vida das mulheres (FERRIS, 1990). Em 2002, o Guidelines on GenderRelated Persecution do ACNUR reconheceu que a violência de gênero perpetrada por atores não estatais, como a família, a comunidade e os grupos militares, é de responsabilidade do Estado que não é capaz de proteger a sua população e, portanto, se torna ele também um agente perpetrador (MARTIN, 2017).

A segunda adição importante foi trazida pelo Protocolo de Maputo. Produzido no âmbito da União Africana em 2003, os Estados africanos reconheceram uma outra categoria de violência de gênero: a econômica. As dificuldades de se constituírem como Estado-nação e de conseguirem desenvolver um crescimento econômico estável desde as décadas de descolonização, afetou desde o início o desenvolvimento de mulheres nos países africanos. No mesmo ano do Protocolo de Maputo, o Guideliness of Sexual and Gender-Based Violence against Refugees, Returnees and Internally Displaced Persons do ACNUR (2003) reconheceu a existência de cinco principais categorias de violência de gênero: a sexual, a física, a emocional e psicológica, a socioeconômica e as agressões ligadas às tradições e práticas culturais dos povos. A dependência da ajuda humanitária para itens básicos de sobrevivência - comida, abrigo, água e saúde - e a falta de oportunidades econômicas e educacionais, o isolamento e a falta de integração, aumentavam a preocupação com novos riscos de vulnerabilidade para as mulheres. Assim, a violência socioeconômica foi conceituada pelo ACNUR (2003) como a falta de oportunidades, a exclusão social, a negação dos direitos civis, sociais, culturais, econômicos e políticos. Esta dimensão foi fundamental para as organizações trabalharem com as violências derivadas da falta de recursos: como o sexo por sobrevivência, a prostituição forçada e o casamento infantil (MARTIN, 2017).

As dificuldades das convenções e tratados internacionais enxergarem as especificidades das mulheres no Sul Global fazem com que as mulheres não tenham suas vozes ouvidas e os seus direitos garantidos (MARTIN, 2017). A partir das reflexões de Spivak (2010), Mohanty (1984) e LOOMBA (1998), uma segunda dimensão aqui é pensar como as categorias de raça/etnia, classe e gênero moldam as vidas das mulheres. Como exemplo, trabalhamos aqui o caso das mulheres sírias abrigadas no campo de refugiados do Zaatari, na Jordânia.

O Zaatari é o maior campo de refugiados do Oriente Médio e abriga hoje 80 mil pessoas. Metade da população é feminina e em torno de $67 \%$ das mulheres que 
habitam o campo são de regiões rurais da Síria: Dara'a (40.1\%), Homs (16.2\%) e Damascos rural (11.3\%). Essas regiões no sul da Síria são caracterizadas por uma maioria árabe, sunita, rural e com pouco acesso à educação (RITCHIE, 2018). Ao adentrar o âmbito do refúgio, as relações sociais - de gênero, classe, etnia e religião - que construíam a sociedade síria, não são simplesmente quebradas. Desde antes do conflito, a sociedade árabe síria é baseada em um sistema patriarcal no qual não apenas o gênero, como também a religião, a condição de pobreza e a cultura são variáveis que denotam as diferentes realidades. As mulheres ricas, alawis e xiitas (aliadas ao governo) possuíam status e lugar no espaço público, no entanto, as mulheres rurais, pobres e sunitas, eram marginalizadas e taxadas como "extremistas" (ABU-ASSAB, 2017). As diferentes identidades impactaram em como as mulheres experimentam o refúgio: enquanto mulheres com fonte de renda moram fora dos campos e possuem experiências de empoderamento, as mulheres dos estratos mais baixos da sociedade síria vivem nos campos de refugiados ou áreas pobres e sua experiência é marcada pelo aumento da violência doméstica e sexual, do casamento infantil forçado, da marginalização, da pobreza, da vulnerabilidade, na degradação de seu status social e do fortalecimento das relações hegemônicas masculinas em seu entorno (CHARLES; DENMAN, 2013; FREEDMAN, 2017; BAKLACIOG LU, 2017; AYOUB, 2017).

Uma vez que a maioria das mulheres do Zaatari são provenientes de Da'aria, região rural e pobre na Síria, elas chegam no campo sem nenhum recurso e possuem sérias dificuldades de garantir um meio de sustento digno. Estima-se que apenas 5 a $10 \%$ das mulheres estão empregadas legalmente, um número seis vezes menor quando comparado às mulheres que residem fora dos campos (RITCHIE, 2017). As mulheres possuem maiores dificuldades de conseguir emprego devido às responsabilidades domésticas, a falta de creches para as crianças, os longos e perigosos percursos que devem percorrer sozinhas e o estigma social de trabalharem fora de casa e na presença de homens (AMJAD et. al, 2017; HUNT; ILLE; SAMMAN, 2017; RITCHIE, 2017). As desigualdades dos papeis de gênero, condicionadas por valores e normas culturais, sociais e históricas, dificultam as mulheres de obter renda ou qualificação em programas de treinamento, os que lhes tornam mais dependentes da assistência internacional (MARTIN, 2017).

Além das questões de gênero e classe acima apresentadas, uma última 
questão importante que deve ser aqui evidenciada é a construção da imagem da mulher refugiada "subjugada" devido a sua etnia, nacionalidade e religião. Hyndman (2000) afirma existir uma violência institucional, geográfica e normativa, pois instituições que gerem o campo o fazem a segundo de suas normas e valores, majoritariamente ocidentais. As organizações universalizam suas políticas sem levar em consideração o gênero e o contexto cultural no qual estão inseridas. Nos campos de refugiados, existem altos índices de violências de gênero, mas que não são denunciadas. A vergonha e o medo de serem excluídas de suas próprias comunidades e de suas famílias, bem como o despreparo das organizações que gerem o campo, silenciam as mulheres. Os programas educativos de prevenções e as informações sobre apoio às vítimas são insuficientes e não alcançam as mulheres. Existe uma baixa confiança nos trabalhadores humanitários e nos seus métodos de abordagem, especialmente se o agressor é o próprio agente humanitário pela falta de pertencimento e de afinidade (HYNDMAN, 2000; FERRIS, 2004; AUBONE; HERNANDEZ, 2013; KRAUSE, 2014).

Ao desconsiderar uma série de fatores históricos, culturais, religiosos e políticos, que diferenciam os países que compõe a região que se convencionou chamar de Oriente Médio, o Ocidente criou uma identidade única da mulher muçulmana oprimida (ABU-LUGHOD, 2013). Nos campos de refugiados, constrói-se a imagem da mulher "subdesenvolvida", como vítima de sua própria cultura e que precisa ser resgatada de culturas bárbaras e subdesenvolvidas (OLIVIUS, 2017). Conforme Ferris (2007) e Cole, Lewis e Qasmiyeh (2017), no contexto de refúgio, é bastante comum que se forme uma nova forma de hierarquização no qual as mulheres refugiadas são vítimas de seus costumes e tradições religiosas e, portanto, necessitam das organizações modernas e seculares para alcançarem a libertação e a igualdade de gênero. Em resposta, a ajuda humanitária emprega esforços para "desenvolver" e "modernizar" a comunidade refugiada por meio de seus programas de empoderamento feminino (OLIVIUS, 2017; COLE; LEWIS; QASMIYEH, 2017). O entendimento de que as organizações seculares já superaram as estruturas, práticas e dinâmicas patriarcais e são ideias para promover o empoderamento de mulheres, pode, na verdade, reproduzir novas formas de violência. Assim, para Cole, Lewis e Qasmieh (2017), a compreensão da ajuda humanitária que salva as mulheres refugiadas remete a novas políticas e práticas orientalistas, nas quais as abordagens 
humanitárias além de construírem imagens, encobrem as experiências e identidades das mulheres que são importantes para promover ações eficientes.

Assim, a violência se revela multidimensional. A violência é de gênero, pois as mulheres sofrem mais para conseguirem se integrarem na sociedade por meio de oportunidades educacionais e laborais e por estarem vulneráveis a violências no âmbito da casa, nos lugares públicos e na ajuda humanitária. A violência é de raça/etnia, por serem desvalorizadas e construídas como mulheres que não possuem capacidades de pensar e falar por si. A violência é epistêmica, pelo silenciamento das mulheres em condição de refúgio, em contraste com os inúmeros artigos de jornais e matérias que visam falar por elas. $E$ a violência é de classe, pela falta de recursos e pelas dificuldades para alcançar novas formas de sustento.

\section{Conclusões}

Este artigo teve como objetivo refletir como as intersecções e diálogos das categorias de gênero, raça e classe, propostas pelo feminismo pós-colonial, permitem pensar as experiências de refúgio e das mulheres no Sul Global. Admitese que ainda existem lacunas a serem preenchidas e é preciso um estudo mais aprofundado das autoras propostas a fim de refinar o argumento, no entanto, o uso da perspectiva pós-colonial permitiu conceber como as dimensões do refúgio - tanto a teórica, quanto a prática - ao trazerem pretensões universais e neutralidade do conhecimento moderno e dos instrumentos internacionais, falham em interpretar e prover respostas às realidades do Sul Global.

As políticas internacionais, as convenções e as práticas no âmbito do refúgio, se revelam, em sua maioria, construídas por apenas um lado do globo e não conseguem contemplar a complexidade das relações existentes entre as identidades e as assimetrias. Ao analisar os instrumentos internacionais foi possível apontar as limitações do conceito tradicional do refúgio e a construção de documentos locais que tenham impacto global. Foi também importante visualizar os diversos motivos que levam as pessoas a se deslocarem não só devido a guerra tradicional, mas também devido aos processos internacionais de descolonização, nacionalismo e globalização. Por fim, foi trabalhada a relação entre a representação do refugiado do 
Sul Global e a mudança das políticas do refúgio ao longo dos anos. Nos três temas abordados, coloca-se como prioritário pensar a nível local, ao mesmo tempo que traçar estratégias teóricas e práticas a nível global.

No que tange uma análise mais específica das mulheres, foi possível demonstrar como os temas da lei internacional do refúgio, das experiências de deslocamento e da construção da imagem da mulher refugiado são temas também atravessados pelas categorias de gênero, raça e etnia. Conseguimos perceber que apesar das mulheres refugiadas não comporem um bloco homogêneo, as categorias de raça, gênero e classe expressam a existência de narrativas e experiências que se assemelham no Sul Global. A lei internacional precisou se modificar e avançar ao longo dos anos para abraçar as principais pessoas afetadas pelos conflitos e deslocamentos forçados, sobretudo, atentando para as especificidades das mulheres. As categorias de classe, raça e gênero que atravessam as normas, no nível internacional, são as mesmas que atravessam os corpos das mulheres e que moldam suas experiências dentro de suas comunidades. As mulheres não são iguais entre si, mas suas experiências podem estar conectadas pelas situações de vulnerabilidade econômica, de discriminação, de violências com bases no gênero e pelas novas formas de salvacionismo e sujeição por parte dos valores, organizações e pessoas ocidentais. Em suma, as categorias permitiram pensar a limitação das políticas, das convenções e dos conceitos sobre violência de gênero e de refúgio que impactam na falta de proteção aos indivíduos e nas ações que denotam novas formas de orientalismo.

Revelou-se aqui que o feminismo pós-colonial interroga premissas do póscolonialismo e do feminismo, suplementando-as com suas próprias preocupações, perspectivas particulares e trazendo folego para trazer novos elementos e interpretações sobre o debate do refúgio e suas políticas internacionais (NAIR, 2017). O feminismo pós-colonial pode ser uma possibilidade para ampliar e aprofundar este debate, trazendo à tona a importância das identidades na construção teórica dos conceitos e dos instrumentos internacionais, bem como, na análise de vivências concretas. Aposta-se também na abertura de maiores possibilidades de diálogo entre as categorias propostas e os estudos dos temas das Relações Internacionais. Se uma disciplina que se diz internacional, de relevância a todos os povos e à todas as regiões, na verdade fala a partir e para um número 
limitado de pessoas - homens, ricos, brancos e ocidentais -, e não consegue dialogar em nome de outras sociedades, como diria Jones (2006), é necessário abrir novas pontes, caminhos e diálogos que sejam capazes de repensar o local e o global a partir das margens.

\section{Referências Bibliográficas}

ABU-LUGHOD, Lila. Do Muslim Women Need Saving? London: Harvard University Press, 2013.

ACNUR. Convenção Relativa ao Estatuto dos Refugiados, 1951. Disponível em: $<$ http://www.acnur.org/t3/fileadmin/Documentos/portugues/BDL/Convencao_relativa_ ao_Estatuto_dos_Refugiados.pdf>. Acesso em: 16 jun. 2019.

Disponível

Protocolo de 1967 Relativo ao Estatuto dos Refugiados, 1967. $<$ http://www.acnur.org/fileadmin/scripts/doc.php?file=fileadmin/Documentos/portugue s/BD_Legal/Instrumentos_Internacionais/Protocolo_de_1967>. Acesso em: 16 jun. 2019.

Declaração de Cartágena, 1984. Disponível em: <https://www.acnur.org/fileadmin/Documentos/portugues/BD_Legal/Instrumentos_Int ernacionais/Declaracao_de_Cartagena.pdf>. Acesso em: 21 jun. 2019.

\section{ACNUR parabeniza Brasil por reconhecer milhares de venezuelanos como refugiados, 2019. Disponível em: < https://www.acnur.org/portugues/2019/12/06/acnur-parabeniza-brasil-por- \\ reconhecer-milhares-de-venezuelanos-como-refugiados/>. Acesso em: 10 jan. 2019.}

AGANTHANGELOU, Anna M.."Sexing" globalization in international relations: migrant sex and domestic workers in Cyprus, Greece, and Turkey. In: CHOWDHRY, Geeta; NAIR, Sheila. Power, Postcolonialism and International Relations: Reading race, gender and class. Routledge: New York, 2002.

AGIER, Michel. Refugiados diante da nova ordem mundial. Tempo Social, São Paulo, v. 18, n. 02, p. 198-2015, 2006. Disponível em: < http://www20.iadb.org/intal/catalogo/PE/2011/08793.pdf>. Acesso em: 16 jun. 2019.

AGUAYO, Sergio; SUHRKE, Astri; ZOLBERG, Aristide R.. Escape from Violence: Conflict and the Refugees Crises in the Developing World. Oxford: Oxford University Press, 1989.

AMJAD, Renad et. al. Examining Barriers to Workforce Inclusion of Syrian Refugees in Jordan. ILO, [S.I.], 2017. Disponível em: < https://betterwork.org/blog/portfolio/discussion-paper-25-examining-barriers-toworkforce-inclusion-of-syrian-refugees-in-jordan/>. Acesso em: 16 jun. 2019. 
AUBONE, Amber; HERNANDEZ, Juan. Assessing Refugee Camp Characteristics and the Occurrence of Sexual Violence: A Preliminary Analysis of the Dadaab Complex. Refugee Survey Quarterly, [S.I.], v. 32, n. 04, p. 22 - 40, 2013.

AYOUB, Maya. Gender, social class and exile: The case of Syrian women in Cairo. In: FREEDMAN, Jane; KIVILCIM, Zeynep; BAKLACIOG LU, Ozgur. A gender approach to the Syrian Refugee Crisis. Routledge Studies in development, mobilities and migration. New York: Routledge, 2017.

BAHRI, Deepika. Feminismo e/no pós-colonialismo. Estudos Feministas, Florianópolis, v. 21, n. 02, p. 659-688, 2013.

BAKLACIOG LU, Ozgur. The violence of tolerated temporality: Syrian women refugees on the outskirts of Istanbul. In: FREEDMAN, Jane; KIVILCIM, Zeynep; BAKLACIOG LU, Ozgur. A gender approach to the Syrian Refugee Crisis. Routledge Studies in development, mobilities and migration. New York: Routledge, 2017.

BETTS, Alexander; LOESCHER, Gil. Refugees in International Relations. In: BETTS, Alexander; LOESCHER, Gil (Eds.). Refugees in International Relations. New York: Oxford University Press, 2011. p. 1-27.

CIDH. Convenção Interamericana para Prevenir, Punir e Erradicar a Violência contra a Mulher, $1994 . \quad$ Disponível em: <http://www.cidh.org/Basicos/Portugues/m.Belem.do.Para.htm>. Acesso em: 21 jun. 2019.

CHARLES, Lorraine; DENMAN, Kate. Syrian and Palestinian Syrian Refugees in Lebanon: the Plight of Women and Children. Journal of International Women's Studies, v. 14, n. 05, [S.I.], p. 96-111, 2013. Disponível em: < https://www.alnap.org/help-library/syrian-and- palestinian-syrian-refugees-in-lebanonthe-plight-of-women-and-children>. Acesso em: 30 out. 2017.

CHIMINI, B. S. The Geopolitics of Refugee Studies: a view from the South. Journal of Refugee Studies, [S.I.], v. 11, n. 04, p. 350-374, 1998.

CHOWDHRY, Geeta; NAIR, Sheila. Power, Postcolonialism and International Relations: Reading race, gender and class. New York: Routledge, 2002.

CHODRWY, Geeta; LING, L. H. M.. Race(ing) International Relations: A Critical Overview of Postcolonial Feminism in International Relations. Oxford Research Encyclopedia of International Studies, [S.I.], 2018. Disponível em: < https://oxfordre.com/internationalstudies/view/10.1093/acrefore/9780190846626.001. 0001/acrefore-9780190846626-e-413>. Acesso em: 21 jun. 2019.

COCKBURN, Cynthia. The Continuum of Violence: A gender perspective on war and Peace. In: GILES, Wenona; HYNDMAN, Jennifer. (Eds.). Sites of Violence: Gender and Conflict Zones. Berkeley, Los Angeles and London: University of California Press, 2004. p. 24-44. 
COLE, Georgina; LEWIS, Chloé; QASMIYEH, Elena Fiddian. 'Faithing' Gender and Responses to Violence in Refugee 127 Communities: Insights from the Sahrawi Refugee Camps andispithe Democratic Republic of Congo. In: KRAUSE, Ulrike; ZISTEL, Buckley Susanne. (Eds.). Gender, Violence, Refugees. Oxford: Berghahn Books, 2017.

CRENSHAW, Kimberle. Mapping the Margins: Intersectionality, Identity Politics, and Violence against Women of Color. Stanford Law Review, v. 43, n. 6, 1991, p. 12411299.

DARBY, Phillip. Development and World Oder. In: DARBY, Phillip. (Ed). From International Relations to Relations International: Postcolonial essays. New York: Routledge, 2016.

DAWN, Chatty. Displacement and Dispossession in the Modern Middle East. New York: Cambbridge University Press, 2010.

FERRIS, Elisabeth G.. Abuse of Power: Sexual Exploitation of Refugee Women. Journal of Women in Culture and Society, Chicago, v. 32, n. 31, p. 584-591, 2007. Disponível em: < http://www.jstor.org/stable/10.1086/510338>. Acesso em: 16 jun. 2019.

$\begin{array}{llll} & \\ \text { CHURCHES. Refugee, Women and Violence [manuscrito]. In: WORLD COUNCIL OF }\end{array}$ http://repository.forcedmigration.org/show_metadata.jsp?pid=fmo:628>. Acesso em: 16 jun. 2019.

Disponíve

Women, War, and Peace. 2. ed. Uppsala: Life \& Peace Institute, 2004. content/uploads/2013/06/nr_2001_03.pdf>. Acesso em: 16 jun. 2019.

FREEDMAN, Jane. Gendering the International Asylum and Refugee Debate. New York: Palgrave Macmillan, 2007.

. Women's experience of forced migration: Gender-based forms of insecurity and the uses of "vulnerability". In: FREEDMAN, Jane; KIVILCIM, Zeynep; BAKLACIOG LU, Ozgur. A gender approach to the Syrian Refugee Crisis. Routledge Studies in development, mobilities and migration. New York: 2017.

GILES, Wenona; HYNDMAN, Jennifer. Introduction: Gender and Conflict in a Global Context. In: GILES, Wenona; HYNDMAN, Jennifer. (Eds.). Sites of Violence: Gender and Conflict Zones. London: University of California Press, 2004. p. 03-23.

GRIMSON, Alejandro. Doces Equívocos de Las Migraciones. Nueva Sociedad, Santiago, v.1, n. 233, p. 34-43, 2011.

HADDAD, Emma. The Refugee in International Society: between sovereigns. New York: Cambridge University Press, 2008. 
HANSEN, Lene. Ontologies, Epistemologies, Methodologies. In: SHEPERD, Laura J.. (Ed.). Gender Matters in Global Politics: A feminist introduction to International Relations. London and New York: Routledge, 2010. p. 17-27.

HOLLIFIELD, James F.. The Politics of International Migration: How can we 'bring the states back in'? In: BRETTELL, Caroline B.; HOLLIFIELD, James F.. (Eds.). Migration Theory: Talking across disciplines. 2. ed. New York and Abingdon: Routledge, 2008. p. 183-238

HOOKS, Bell. Feminist theory: from margin to center. Boston: South End Press, 1984.

HUNT, Abigail; ILLE, Dina Mansour; SAMMAN, Emma. Syrian women refugees in Jordan: opportunity in the gig economy? ODI, London, 2017. Disponível em: < https://www.odi.org/syrian-refugees-jordan-gig-economy>. Acesso em: 16 jun. 2019.

HYNDMAN, Jennifer. Managing displacement: refugees and the politics of humanitarianism. London: Univeristy of Minnesota Press, 2000.

JONES, Gruffydd Branwen. Introduction. In: JONES, Gruffydd Branwen (Ed.). Decolonizing International Relations. Maryland: Rowman \& LittleField, 2006.

JUBILUT, Liliana Lyra; MADUREIRA, André de Lima. Os desafios de proteção aos refugiados e migrantes forçados no marco de Cartagena +30 . Revista Interdisciplinar de Mobilidade Humana, v. 22, n. 43, 2014. Disponível em: $<$ http://www.scielo.br/scielo.php?script=sci_arttext\&pid=S198085852014000200002>. Acesso em: 21 jun 2019.

KOFMAN, Eleonore, et al. Gender and International Migration in Europe. London and New York: Routledge, 2000.

KRAUSE, Ulrike. Analysis of empowerment of refugee women in camps and settlements. Journal of Internal Displacement, [S.I.], v. 04, n. 01, p. 29-52, 2014.

KRAUSE, Ulrike; ZISTEL, Buckley Susanne. Gender, Violence, Refugee: An Introduction. In: KRAUSE, Ulrike; ZISTEL, Buckley Susanne. (Eds.). Gender, Violence, Refugees. Oxford: Berghahn Books, 2017. p. 01-18.

KRISHNA, Sankaran. Race, Amnesia and the Education of International Relations. In: JONES, Gruffydd Branwen. (Ed.). Decolonizing International Relations. Maryland: Rowman \& LittleField, 2006.

LOOMBA, Ania. Colonialism/Postcolonial. Routledge: London, 1998.

LUGONES, Maria. The Coloniality of Gender. Worlds and Knowledges, [S.I.], p. 0117, 2008.

MARTIN, Susan F.. UNHCR Policy on Refugee Women: A 25-Year Retrospective. sise: In: KRAUSE, Ulrike; ZISTEL, Buckley Susanne. (Eds.). Gender, Violence, Refugees. Oxford: Berghahn Books, 2017. 
MOHANTY, Chandra Talpade. Under Western Eyes: Feminist Scholarship and Colonial Discourses. The Discourse of Humanism, [S.I.], v. 13, n. 01, p. 333-358, 1984.

MOREIRA, Julia Bertino; ROCHA, Rossana Reis. Regime Internacional para Refugiados: Mudanças e Desafios. Revista Sociologia Política, Curitiba, v. 18, n. 37, p. 17-30, 2010.

NAIR, Sheila. Postcolonialism. In: MCGLINCHEY, Stephen; SCHEINPFLUG, Christian; WALTERS, Rosie. (Eds.). International Relations Theory. Bristol: EInternational Relations Publishing, 2017.

OLIVIUS, Elisabeth. Refugees, Global Governance and the Local Politics of 58 Violence against Women:sẸ. In: KRAUSE, Ulrike; ZISTEL, Buckley Susanne. (Eds.). Gender, Violence, Refugees. Oxford: Berghahn Books, 2017.

ONU MULHERES. Declaração das Nações Unidas para a Eliminação da Violência Contra a Mulher, 1993. Disponível em: < http://www.onumulheres.org.br/wpcontent/uploads/2013/03/convencao_cedaw1.pdf>. Acesso em: 21 jun. 2019.

QUIJANO, Anibal. Colonialidade do Poder, eurocentrismo e América Latina. Trabalho apresentando no Consejo Latinoamericano de Ciências Sociales (CLACSO), Buenos Aires, $2005 . \quad$ Disponível em: < http://biblioteca.clacso.edu.ar/clacso/sur-sur/20100624103322/12_Quijano.pdf>.

Acesso em: 20 jun. 2019.

Colonialidade do Poder e Classificação Social. In: SANTOS, de Souza Boaventura; MENESES, Maria Paula (Eds.). Epistemologias do Sul. Coimbra: CES, 2009. p. 73-118.

REIS, Rossana Rocha. Soberania, direitos humanos e migrações internacionais. Revista Brasileira de Ciências Sociais, [S.I.], v. 19, n. 55, p. 149-164, 2004. Disponível em: <http://www.scielo.br/pdf/rbcsoc/v19n55/a09v1955.pdf>. Acesso em: 16 jun. 2019.

RITCHIE, Holly A. Uncertain livelihoods in refugee environments Between risk and tradition for Syrian refugee women in Jordan. SLRS, London, 2017. Disponível em:

https://assets.publishing.service.gov.uk/media/Uncertain_livelihoods_in_refugee_env ironments_-

_Between_risk_and_tradition_for_Syrian_refugee_women_in_Jordan.pdf $>$. Acesso em: 16 jun. 2019.

RITCHIE, Holly A.. Gender and enterprise in fragile refugee settings: female empowerment amidst male emasculation-a challenge to local integration? Special Issue: Gender, sexuality, and violence in humanitarian crises. Disasters, v. 41, n. 01, 2018.

SAID, Edward. Orientalismo: o oriente como invenção do ocidente. São Paulo: Companhia das Letras, 1990. 
ensaios. São Paulo: Companhia das Letras, 2003. p.46-60.

SCOTT, Joan W. Gênero: uma categoria útil de análise histórica. Educação e Realidade, v. 15, n. 02, Porto Alegre, 1990.

SEIFERT, Ruth. The second front: The Loc of Sexual Violence in Wars. Women's Studies International Forum, v. 19, n. 1., p. 33-43, 1996.

SETH, Sanjay. Introduction. In: SETH, Sanjay. Postcolonial Theory and International Relations: a critical introduction. London: Routledge, 2013.

SPIVAK, Chakravorty Gayatri. Pode o subalterno falar? UFMG: Belo Horizonte, 2010.

TICKNER, Ann J. Gendering world politics: Issues and approaches in the postcold war era. New York: Columbia University Press, 2001.

Feminist Perspectives on International Relations. In: CARLSNAES, Walter; RISSE, Thomas; SIMMONS, Beth A. (Eds.). Handbook of International Relations. New York: SAGE, 2002. p. 275-291.

. Gender in International Relations: Feminist Perspectives on Achieving Global Security. Columbia University Press: New York, 1992.

TROELLER, Gary G.. Refugees in Contemporary International Relations: reconciling state and individual sovereignty. In: NEW ISSUES IN REFUGEE RESEARCH. UNHCR Regional Representative for the Baltic and Nordic countries. Estocolmo, 2003. Disponível em: < http://www.unhcr.org/research/working/3e71f1b64/refugees-contemporaryinternational-relations-reconciling-state-individual.html>. Acesso em: 16 jun. 2019.

UNHCR. Global Trends: Forced Displacement in 2018. UNHCR, [S.I.], 2019. Disponível em:

https://www.unhcr.org/search?comid=56b079c44\&\&cid=49aea93aba\&tags=globaltre nds> Acesso em: 16 jun. 2019.

UNHCR. Sexual and Gender-Based Violence against Refugees, Returnees and Internally Displaced Persons: guidelines for prevention and response. [S.I.], 2003. Disponível em: <https://www.unicef.org/emerg/files/gl_sgbv03.pdf>. Acesso em: 02 de nov. 2017.

WEINER, Myron. Security, stability and International migration. International Security, [S.I.], v. 17, n. 03, p. 91-126, 1992. Disponível em: < https://www.jstor.org/stable/2539131>. Acesso em: 16 jun. 2019.

WIBBEN, Annick T.R.. Feminist International Relations: Old Debates and New Directions. Brown Journal of World Affairs, [S.I.], v. 10, n. 02, p. 97-114, 2004. Disponível em: < https://www.jstor.org/stable/24590524>. Acesso em: 16 jun. 2019. 
ZEHFUSS, Maja. Critical Theory, Poststructuralism, and Postcolonialism. In: CARLSNAES, Walter; RISSE, Thomas; SIMMONS, Beath A. Handbook of International Relations. London: SAGE, 2013. 